http://jmscr.igmpublication.org/home/ ISSN (e)-2347-176x ISSN (p) 2455-0450

crossref DOI: https://dx.doi.org/10.18535/jmscr/v8i12.49

\title{
Study of Prevalence of Hypertension and its associated risk factors among adult tribal population (18 years and above) in a rural community of Katihar District, Bihar
}

\author{
Authors \\ Dr Urmi Poddar ${ }^{1}$, Dr Prawin Chandra ${ }^{2 *}$, Dr Sahid Iqbal ${ }^{3}$ \\ ${ }^{1}$ Medical officer incharge, PHC Mansahi, Katihar \\ ${ }^{2,3}$ Associate Professor Department of Community Medicine, Katihar Medical College, Katihar \\ *Corresponding Author \\ Dr Prawin Chandra
}

Associate Professor Department of Community Medicine, Katihar Medical College, Katihar, India

\begin{abstract}
Background: The size of elderly segment of population is increasing in developing countries as the latter undergo a demographic transition with a concomitant increase in life expectancy. Indeed, it is estimated that by the year 2025 the majority of the people worldwide will reside in developing countries. Developing countries are thus likely to face an enormous burden of chronic non communicable disease in the near future. Of these diseases, hypertension is one of the most important treatable causes of mortality and morbidity in the elderly population. Studies have shown that tribal population in India are also experiencing this burden.

Objective: To measure the prevalence of hypertension and identify its risk factors.

Methods: A community based cross- sectional study was conducted in 1800 tribal population of 18 years and above in three tribal villages under Uttari Simaria of Korha block, Katihar.

Result: In 1800 population $51.7 \%$ were male and $48.3 \%$ were female. The Overall prevalence of hypertension was found $14.8 \%$. in which $16.3 \%$ were males and $13.1 \%$ were females. Prevalence of hypertension was found greater in people taking non-vegetarian diet $18.1 \%$.

Conclusion: Appropriate knowledge intervention strategies need to be adopted to increase awareness and treatment practices of hypertension among tribals.

Keywords: Prevalance, Hypertension, Non-Communicable Disease, Tribals, Awareness, Treatment.
\end{abstract}

\section{Introduction}

The Framingham Study conducted in the USA showed that the higher levels of blood pressure were related to higher rates of mortality from Coronary Heart Disease (CHD) and stroke. ${ }^{1}$ Lauridsen and Gyntelberg (1979) found that $75 \%$ of hypertensive persons had major cardiovascular complications. $^{2}$
The study conducted in the urban population of Siliguri, West Bengal showed that Ischemic Heart A number of randomized control trials in developed countries have establishment of high blood pressure in the elderly population significantly reduces cardiovascular morbidity and mortality. $3,4,5,6$ Several community based investigations have served to emphasize that hypertension is rapidly emerging as a major health 
problems also in developing contries. ${ }^{7}$ As per estimates, the number of person with hypertension in India will nearly double from 118.2 million in 2000 to 213.5 million in $2025 .^{8}$ Disease (IHD) was significantly associated with hypertension. ${ }^{9}$

The concept of normal and raised blood pressure is a widely discussed phenomenon and views do not quite agree with each other. Sir George Pickering started that the dividing line between "normotension" and "hypertension" is nothing more than artefact. ${ }^{10}$ Pickering stated also that essential hypertension is a quantitative deviation from the norm and hence the difference between hypertension and normotension is one degree and not of kind. ${ }^{11}$ Sir George Pickering first formulated a concept that blood pressure in a population is distributed between normotension and hypertension. ${ }^{12}$

World Health Organization (WHO)-International Society Of Hypertension (WHO-ISH) defined hypertension as either a systolic Blood Pressure as either a Systolic Blood Pressure $\geq 140 \mathrm{mmHg}$ and /or treatment with anti-hypertensive medications. ${ }^{13}$ In some developed countries, up to $25 \%$ of adults have diastolic pressure above 90mmHg. ${ }^{14}$ In developing countries the prevalence of hypertension varies from $10 \%$ to as much as $20 \%$ among adults. ${ }^{15}$

In India in a well planned study (1978) the prevalence of hypertension was found as 5.9 and 6.9 percent in males and females respectively in urban population (20-60years) of Rohtak. ${ }^{16}$ In another study (1977) conducted in s village of Haryana the prevalence of hypertension was observed as 3.5 and 3.59 percent in males and females respectively. ${ }^{17}$ It is estimated that $21 \%$ of Indians have raised blood pressure (2014). ${ }^{18}$ Several Community based studies in India have estimated the prevalence of hypertension in urban as well as rural areas. The meta analysis of eight studies carried out gives a pooled prevalence rate of 164.2 per thousand in urban areas that hypertension is present in $25 \%$ urban and $10 \%$ rural subjects in India. ${ }^{19}$ In a rural community of Varanasi district the prevalence of hypertension was fond to be 7.19 percent. ${ }^{20}$ Study conducted in a rural area of $J \& K$ state, India the overall prevalence of hypertension was observed as 8.31 percent. $^{21}$

In a study conducted among tribal labour population in Gujarat the prevalence of hypertension was found to be $16.9 \% .^{22}$ However a study among tribal "Oraon" population of Orissa revealed lower prevalence of hypertension$4.6 / 1000$ population. ${ }^{23}$ In contrast a study among primitive tribes of Orissa reported prevalence of hypertension among males and females as 31.8 and 42.2 percent respectively. ${ }^{24} \mathrm{~A}$ study was undertaken among aboriginal Nicobarese tribe living in Car Nicobar Island, India has documented high prevalence of hypertension $50.5 \% .^{25}$ Epidemiological study carried out among the Lepchas of Sikkim has documented hypertension prevalence of $31.9 \%$ among rural males and $25.0 \%$ among rural females (by using older WHO criteria for hypertension). ${ }^{26}$

\section{Aims and Objective}

1. To determine the prevalence of hypertension in a tribal population of age 18 years and above in rural community.

2. To examine the impact of the various known risk factors responsible for variations of blood pressure (18 years and above) of tribal population in a rural community.

\section{Material and Method}

A community based cross sectional study will be a carried out in a tribal population of 18years and above in three tribal villages under Uttari Simaria GP of Korha block, Katihar district, Bihar during 2017. These villages with tribal population are situated in the rural field practice area of Katihar Medical College, Katihar.

On the basis of that prevalence of hypertension the sample size of the present study adopting the formula

$$
n=\frac{Z^{2} \alpha / 2 \times \mathrm{PQ}}{\Sigma^{2}}
$$




\section{Results}

Table I Age and Sex Distribution

\begin{tabular}{|l|c|c|c|}
\hline $\begin{array}{l}\text { Age In } \\
\text { Years }\end{array}$ & Male & Female & Total \\
\hline $\mathbf{1 8 - 2 9}$ & $170(9.4 \%)$ & $192(10.7 \%)$ & $362(20.1 \%)$ \\
\hline $\mathbf{3 0 - 3 9}$ & $135(7.5 \%)$ & $162(9 \%)$ & $297(16.5 \%)$ \\
\hline $\mathbf{4 0 - 4 9}$ & $198(11 \%)$ & $172(9.6 \%)$ & $370(20.6 \%)$ \\
\hline $\mathbf{5 0 - 5 9}$ & $254(14.1 \%)$ & $191(10.6 \%)$ & $445(24.7 \%)$ \\
\hline$\geq \mathbf{6 0}$ & $174(9.7)$ & $152(8.4 \%)$ & $326(18.1 \%)$ \\
\hline Total & $931(51.7 \%)$ & $869(48.3 \%)$ & $1800(100 \%)$ \\
\hline
\end{tabular}

Table 2 Age wise prevalence of hypertension in study subjects

\begin{tabular}{|l|c|c|c|}
\hline $\begin{array}{c}\text { Age in } \\
\text { Years }\end{array}$ & Hypertensive & Normotensive & Total \\
\hline $\mathbf{1 8 - 2 9}$ & $31(11.6 \%)$ & $262(17.1 \%)$ & $293(16.3 \%)$ \\
\hline $\mathbf{3 0 - 3 9}$ & $38(14.3 \%)$ & $297(19.4 \%)$ & $335(18.6 \%)$ \\
\hline $\mathbf{4 0 - 4 9}$ & $55(20.7 \%)$ & $352(122.9 \%)$ & $407(22.6 \%)$ \\
\hline $\mathbf{5 0 - 5 9}$ & $63(23.7 \%)$ & $356(23.2 \%)$ & $419(23.3 \%)$ \\
\hline$\geq=\mathbf{6 0}$ & $79(29.7 \%)$ & $267(17.4 \%)$ & $346(19.2 \%)$ \\
\hline Total & $266(100 \%)$ & $1534(100 \%)$ & $1800(100 \%)$ \\
\hline
\end{tabular}

Table 3 Sex-wise prevalence of hypertension in study subjects

\begin{tabular}{|l|c|c|c|}
\hline & Hypertensive & Normotensive & Total \\
\hline Male & $157(16.3 \%)$ & $809(83.7 \%)$ & $966(53.7 \%)$ \\
\hline Female & $109(13.1 \%)$ & $725(86.9 \%)$ & $834(46.3 \%)$ \\
\hline Total & $266(14.8 \%)$ & $1534(85.2 \%)$ & $1800(100 \%)$ \\
\hline
\end{tabular}

Table 4 Showing prevalence of hypertension as per Salt Intake among study subjects

\begin{tabular}{|l|c|c|c|}
\hline Salt Intake & Hypertensive & Normotensive & Total \\
\hline $\begin{array}{l}\text { Extra } \\
\text { Salt( }>\text { 5gm/dl) }\end{array}$ & $74(35.1 \%)$ & $137(6.5 \%)$ & $211(11.7 \%)$ \\
\hline Normal Salt & $182(11.6 \%)$ & $1407(88.5 \%)$ & $1589(88.3 \%)$ \\
\hline Total & $266(14.8 \%)$ & $1534(85.2 \%)$ & $1800(100 \%)$ \\
\hline
\end{tabular}

Table 5 Showing prevalence of Hypertension among study population as per dietary habit

\begin{tabular}{|l|c|c|c|}
\hline Group & Hypertension & Normotensive & Total \\
\hline Vegetarian & $37(6.9 \%)$ & $496(93.1 \%)$ & $533(29.6 \%)$ \\
\hline $\begin{array}{l}\text { Non- } \\
\text { Vegetarian }\end{array}$ & $229(18.1 \%)$ & $1038(81.9 \%)$ & $1267(70.4 \%)$ \\
\hline Total & $266(14.8 \%)$ & $1534(85.2 \%)$ & $1800(100 \%)$ \\
\hline
\end{tabular}

Table 6 Showing prevalence of hypertension among study population with habit of chewing tobacco

\begin{tabular}{|l|c|c|c|}
\hline $\begin{array}{l}\text { Tobacco } \\
\text { Chewing }\end{array}$ & Hypertensive & Normotensive & Total \\
\hline Yes & $208(45.8 \%)$ & $246(54.2 \%)$ & $454(25.2 \%)$ \\
\hline No & $58(4.3 \%)$ & $1288(95.7 \%)$ & $1346(74.8 \%)$ \\
\hline Total & $266(14.8 \%)$ & $1534(85.2 \%)$ & $1800(100 \%)$ \\
\hline
\end{tabular}

Table 7 Prevalence of Hypertension in Smokers

\begin{tabular}{|l|c|c|c|}
\hline Smoking & Hypertensive & Normotensive & Total \\
\hline Yes & $161(46.8 \%)$ & $183(53.2 \%)$ & $344(19.1 \%)$ \\
\hline No & $105(7.2 \%)$ & $1351(92.8 \%)$ & $1456(80.9 \%)$ \\
\hline Total & $266(14.8 \%)$ & $1534(85.2 \%)$ & $1800(100 \%)$ \\
\hline
\end{tabular}

Table 8 Prevalence of Hypertension in Alcoholic

\begin{tabular}{|l|c|c|c|}
\hline Alcoholic & Hypertensive & Normotensive & Total \\
\hline Yes & $183(19.9 \%)$ & $735(80.1 \%)$ & $918(51 \%)$ \\
\hline No & $83(9.4 \%)$ & $799(90.6 \%)$ & $882(49 \%)$ \\
\hline Total & $266(14.8 \%)$ & $1534(85.2 \%)$ & $1800(100 \%)$ \\
\hline
\end{tabular}

\section{Discussion}

In the present study, Table 1 shows that the percentage distribution of age in male and female participations, maximum number of males was in the age group of 50-59 years and female were in the age group of 18-29 years and for convinence persons aged 60 years and above have been grouped in a single category. Table 2 shows age wise prevalence of hypertension it is seen that 266 persons are found hypertensives we also observe that the percentage of hypertensive subjects was found to be minimum in the age group 18-29 years $(11.6 \%)$ and maximum in the age group 60 and above (21.7\%), as the age increases the percentage of hypertension also increases. Table 3 Sex-wise prevalence of hypertension in study subjects, we can observe that the percentage of hypertension was found to be more in males $(16.3 \%)$ as compared to females $(13.1 \%)$. Table 4 Showing prevalence of hypertension as per Salt Intake among study subjects shows that we can observe that the percentage of hypertension was found more on subjects taking extra salt $35.1 \%$. Table 5 Shows prevalence of Hypertension among study population as per dietary habit shows we can observe that the maximum percentage of hypertension was found to be maximum in subjects taking non-vegetarian diet $18.1 \%$.Table6 shows prevalence of hypertension among study population with habit of chewing tobacco, we can observe that the maximum percentage of hypertensive subject was found in tobacco chewing $45.8 \%$. Table 7 shows Prevalence of Hypertensives in smokers shows we can observe that the percentage of hypertensives among 
smokers in $46.8 \%$.Table 8 Prevalence of Hypertension in Alcoholic shows we can observe that the percentage of hypertensives subjects who are alcoholic are $19.5 \%$.

\section{Summary and Conclusion}

Hypertension is the commonest cardiovascular disease, posing a major public health challenge to the societies in socio economic and epidemiological transition. India, undergoing this transition is burdened with problem of increasing prevalence of hypertension especially in rural areas. Although traditional population around the world were often believed to have low blood pressure, gradually with changing socioeconomic environment, marked increase in blood pressure has not been noted. Tribal populations are more vulnerable as they live in difficult or remote areas with lack of proper health facility and poor health seeking behaviour. With this objective, a crosssectional study was conducted to find the prevalence and associated risk factors of hypertension in adults ( $>18$ years) in rural tribal population.

\section{References}

1. Dawber, T.R, Kannel, W.B, Kagan, A.K, Donabedin, R.K,Mc Namara, PM, and Pearson G(1967), Environmental factors in Hypertension, in the "Epidemiology of Hypertension" edited by Stamler, J, Stamler, R and Pullman T.n, Grune and Stratton, New York and London, 225.

2. Laridsen, L and Gyntelberg,F.(1979).A clinical follow up five years after screening for hypertension in Copenhagen males aged 40-59, International J. Epid, 3,11-14.

3. Amery, A et al, Mortality and Morbidity results from the European Working Party on High Blood Pressure in Elderly Tribal Lancet,1985,1:1349-1354

4. Dahlof, B.et. al. Morbidity and Mortality in Swedish trial in old patients with hypertension

(STOP-Hypertension).

Lancet, 1991, 338, 1281-1285

5. SHEP Co-operative Research Group. Prevention of stroke by antihypertensive drug treatment in older persons with isolated systolic hypertension. Final results of the Systolic Hypertension in the Elderly Programme (SHEP), Journal of the American Medical Association, 1991, 265, 3255-326.

6. Staessen, J A et.al, Randomized double blind comparison of placebo and active treatment for older patient with isolates systolic hypertension, The Systolic Hypertension in Europe (syst-Eur)Trial Investigators,Lancet, 1997,350,757-764.

7. Fuentes R, et. al, Hypertensionn in developing economies, a review of population based studies carried out 1980 to 1998 Journal of Hypertension 2000, 18,521-529.

8. Kearney PM, Whelton M, Reynolds K, He $\mathrm{J}$, analysis of Worldwide data, Lancet, 2005, 365(9455):217-223

9. Mondal Sukanta, Saha JB, Mondal Sankar Chandra, Bhattacharya RN, Chakraborty Manashi, Pal Partha Pratim. Prevalence of Ischemic Heart Disease Among Urban Population of Siliguri, West Bengal, Indian the American Medical Association, 1991,265,3255-3264

10. Pickering, G (1968), High blood pressure, $2^{\text {nd }}$ ed, J\&A, Churchill London.

11. Pickering,G.(1961), The nature of essential hypertension. J\&A, Churchill, London.

12. WHO (1996) Technical Report Series No.862.

13. 1999, World Health OrganizationInternational Society of Hypertension, Guideline for the management of Hypertension, Guidelines Sub Committee, Journal of Hypertension, 1999, 17,151-183.
14. WHO (1986) Technical
Report

SeriesNo.732. 
15. WHO (1983) Technical Report Service No.686.

16. Gupta, S.P. et al.(1978), Ind. Heart $\mathrm{J}, 30: 315$.

17. Gupta S.P et al.(1977), Ind. Heart J.,29:53.

18. World Health Organization, NCD Country Profiles,2014. Available at: www,who.int $/ \mathrm{mmhh} /$ countries/inden.pdf ua $=1$.

19. Indian Council of Medical Research. Study on assessment of burden of noncommunicable 20\%Diseases pdf.

20. Sharma R, Baldev, Singh Bhupinder. A Study of Hypertension in adult population (20-60 years)of rural area of J\&K state. Indian Journal of Community Medicine Vol 12 No.4 October-December.1997

21. Hypertension Study Group-WHO, Prevalence awareness, treatment and control of hypertension and control of hypertension among the elderly in Bangladesh and India: a multicentric study-Bulletin of World Health Organization, 2001 , 79:490-500.

22. Rajnarayan R. Tiwari, Hypertension and Epidemiological Factors among Tribal Labour Population in Gujrat. Indian Journal of Public Healthhh, Vol.52,Mo 3,July-September,2008.

23. Dash, SC, Sundaram K.R, Swain PK, Blood Pressure Profile, urinary sodium and body in the "Oraon" rural and urban tribal community. J Associ Physicians India, $1994 ; 42: 878-80$.

24. Kerketta AS, Bulliyya G, Babu BV, Mahapatra population among for primitive tribes of Orissa in India:A clinicepidemiological study Z Gerontol Geriatr. 2009;42:53-9.
25. Manimunda SP, Suguman AP, Bengal V, Balakrishna N, Rao VM and Pesala KS. Association of hypertension with risk factors and hypertension related behaviour among the aboriginal Nicobarese tribe living in Car Nicobar Island, India. Indian Journal of Medical RESEARCH,2011 March,133(3):287-293.

26. Mukopadhyay B and Mukhopadhyays, Blood Pressure and its Biocultre Correlates Among the Lepchas of Sikkim, India: A Micro level Epidemiological Study, Coll. Antropol 25(2001)1:97-110. 